\title{
Transcatheter aortic paravalvular leak closure using 3 Amplatzer Vascular Plug III devices in a child
}

\author{
Roland Fiszer $^{1}$, Grzegorz Smolka², Malgorzata Szkutnik ${ }^{3}$, Jacek Białkowski \\ ${ }^{1}$ Silesian Center for Heart Diseases, Katowice, Poland \\ ${ }^{2} 3^{\text {rd }}$ Division of Cardiology, Medical University of Silesia, Katowice, Poland \\ ${ }^{3}$ Department of Congenital Heart Diseases and Pediatric Cardiology, Medical University of Silesia, Zabrze, Poland
}

Postep Kardiol Inter 2015; 11, 2 (40): 156-157

DOI: $10.5114 /$ pwki.2015.52293

Paravalvular leak (PVL) is usually related to disruption of prosthetic valve sewing ring sutures. Many previous reports have described transcatheter paravalvular leak closure in adult patients [1-4], but those describing such a procedure in children are scarce.

A 16-year-old boy underwent an aortic valve replacement (AVR) with a stented bioprosthesis Hancock $23 \mathrm{~mm}$ due to combined aortic stenosis and insufficiency. Soon after, a significant paravalvular leak was detected and initially managed medically. However, within the next 5 months the patient became breathless on exertion and developed significant left ventricular dilatation. Paravalvular leak closure was performed under general anesthesia, with transesophageal echocardiographic (TEE) and angiographic guidance. Aortography confirmed grade 3 aortic regurgitation (Figure $1 \mathrm{~A}$ ). The paravalvular leak size was evaluated in TEE at $4 \times 3 \mathrm{~mm}$. It was identified as posterior, from the noncoronary Valsalva sinus into the left ventricle (LV). The defect was easily crossed using two JR catheters and hydrophilic wires, then Amplatz extra-stiff guidewires were introduced from both femoral arteries into the LV. Over these, $120 \mathrm{~cm}$ long sheaths ( $6 \mathrm{Fr}$ and $7 \mathrm{Fr}$ ) were advanced through the paravalvular leak. No obstruction during the crossing was met, which was considered confirmatory of the defect size exceeding what was expected from TEE. Accordingly, the decision was taken to implant 3 devices in order to avoid a residual shunt. Two 8/4 Vascular Plugs type III were implanted and one $6 / 3 \mathrm{~mm}$ Vascular Plug type III (St Jude Medical Inc.). After sequential opening of the distal discs in the LV all plugs were withdrawn simultaneously to the level of the paravalvular leak orifice. The proximal discs were then opened (Figure 1 B) with immediate complete closure of the shunt on TEE (Figure $1 \mathrm{C}$ ). Prior to devices release, proper function of the prosthetic valve was confirmed by TEE. Control aortography showed proper position of devices without Ao-LV shunt (Figure $1 \mathrm{D}$ ). Fluoroscopy time was $18.5 \mathrm{~min}$. The next morning the patient underwent transthoracic echocardiography which confirmed a good procedure result with normal function of the prosthetic aortic valve, without any regurgitant jet. The patient was discharged 3 days after the procedure on $150 \mathrm{mg}$ Aspirin q.d.

Early mortality in redo AVR reaches 3.5-6\% [1]. Transcatheter treatment has been constantly developing during the last years. Transcatheter PVL closure was initially performed with devices dedicated to patent ductus arteriosus, ventricular septal defect and atrial septal defect [2]. In our and others' opinion, especially useful for such purposes is Amplatzer Vascular Plug type III [3]. Lack of internal fabric, which could potentially promote clot formation, may be considered a major disadvantage of the device. We suspect that use of one or two bigger plugs in the hereby-presented case might result in residual leaking and possibly hemolysis [4]. To avoid such complications we chose 3 plugs to ensure tight as possible filling of the defect. Simultaneous implantation of multiple devices increases the chance of final success, which was described previously [3].

\section{Conflict of interest}

The authors declare no conflict of interest.

\section{Corresponding author:}

Prof. Jacek Białkowski MD, PhD, Śląskie Centrum Chorób Serca, 9 M. Curie-Skłodowskiej St, 41-800 Zabrze, Poland, phone: +48 32 271 34 01, e-mail: jabi_med@poczta.onet.pl

Received: 27.02.2015, accepted: 19.04.2015. 

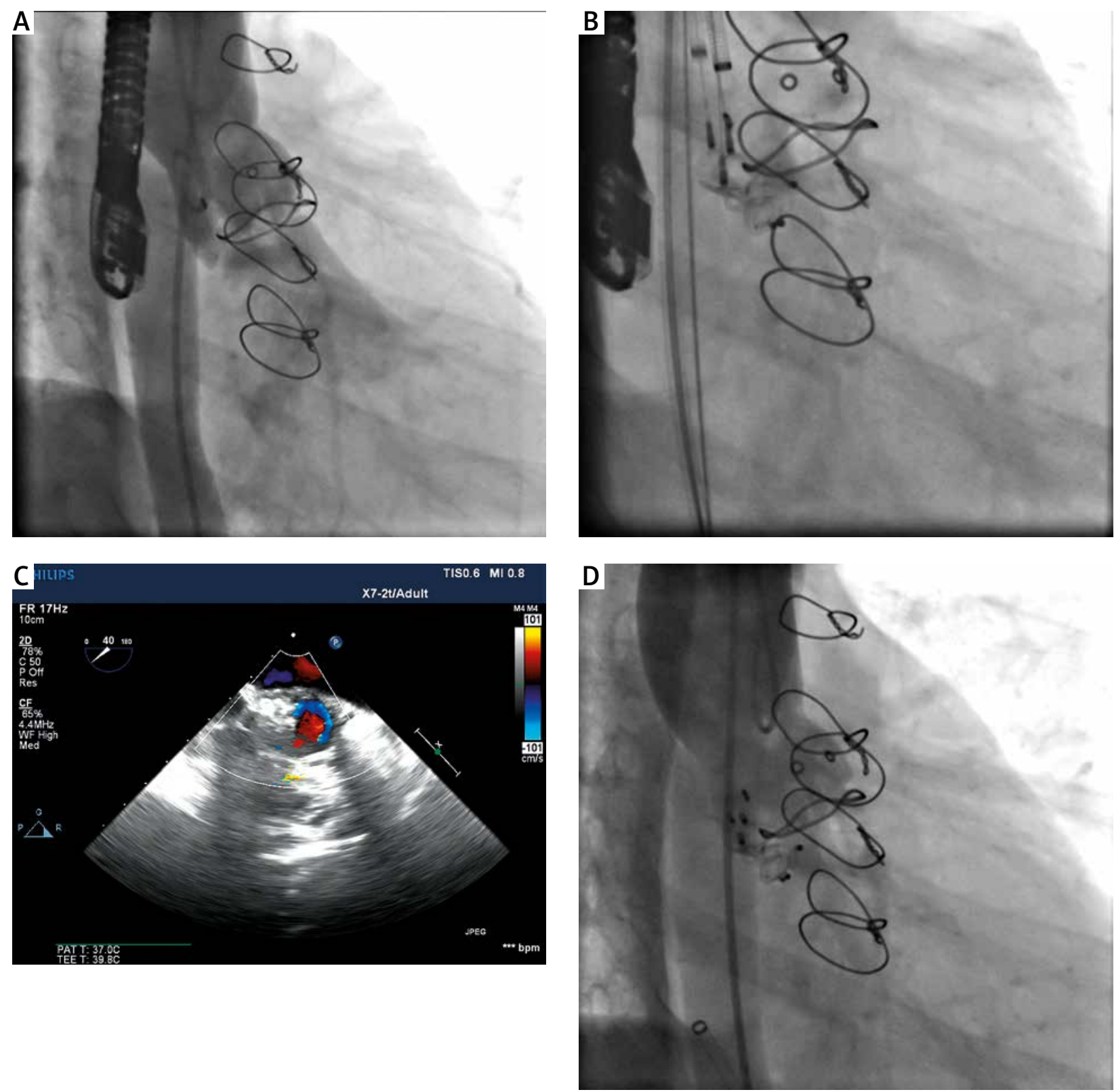

Figure 1. A - Aortography RAO 30 Caud 30. Paravalvular leak from posterior Valsalva sinus to LV. B - Three Amplatzer Vascular Plug 3 devices closing paravalvular leak still connected with delivery system. C - Transesophageal echocardiographic scan - aortic short axis view. Complete paravalvular aortic leak closure with 3 devices. D - Control aortography after procedure (RAO 30 Caud 30 projection). Complete closure of previously observed paravalvular leak

\section{References}

1. Leontyev S, Borger MA, Daviervala P, et al. Redo aortic valve surgery early and late outcome. Ann Thorac Surg 2011; 91: 1120-6.

2. Pate GE, Zubaidi Al, Chandavimol M, et al. Percutaneous closure of prostetetic paravalvular leaks: case series and review. Catheter Cardiovasc Interv 2006; 68; 528-33.

3. Smolka G, Pysz P, Wojakowski W, et al. Clinical manifestations of heart failure abate with transcatheter aortic paravalvular leak closure using Amplatzer Vascular plug II and III devices. J Invasive Cardiol 2013; 25: 226-31.
4. Sanchez-Recalde A, Moreno R, Galeote G, et al. Immediate and mid-term clinical course after percutaneous closure of paravalvular leakage. Rev Esp Cardiol 2014; 67: 615-23. 